\title{
Publisher Correction to: The response of pollen-transport networks to landscape-scale climate variation
}

\author{
Christine Urbanowicz ${ }^{1}$ [D . Ross A. Virginia ${ }^{2} \cdot$ Rebecca E. Irwin ${ }^{1,3}$
}

Published online: 14 March 2018

c) Springer-Verlag GmbH Germany, part of Springer Nature 2018

Correction to: Polar Biol (2017) 40:2253-2263

https://doi.org/10.1007/s00300-017-2138-8

The above-mentioned article was originally scheduled for publication in the special issue on Ecology of Tundra Arthropods with guest editors Toke T. Høye and Lauren E. Culler.
Erroneously, the article was published in Polar Biology, Volume 40, Issue 11, November, 2017. The publisher sincerely apologizes to the guest editors and the authors for the inconvenience caused.

The original article can be found online at https://doi.org/10.1007/ s00300-017-2138-8.

Christine Urbanowicz

Christine.Urbanowicz@Dartmouth.edu

1 Department of Biology, Dartmouth College, Hanover, NH 03755, USA

2 Environmental Studies Program, Dartmouth College, Hanover, NH 03755, USA

3 Present Address: Department of Applied Ecology, North Carolina State University, Raleigh, NC 27695, USA 